\title{
MICROSCOPIC ANALYSIS OF CHIPPED STONE TOOLS FROM BARTON RAMIE, BRITISH HONDURAS
}

Richard WILK

This paper was originally intented to be a firm functional base for the re-organization of the standard Kidder-Coe typology of Mayan stone tools, through the use of wear-pattern analysis. In the present state however, this paper is only a bare beginning due to the limited nature of the assemblage examined. In the future I hope to combine re-examinations of existing collections with the trial classification of an entire collection excavated by the Corozal Proyect under Dr. Norman Hammond's direction. Re-examinations of published material will be presented in the same way as this report, and in the case of Seibal collections, Dr. Gordon Willey has invited me to present my analysis as an appendix to his own report. Eventually, it is hoped, a taxonomic system for Mayan stone tools will be evolved which reflects as closely as possible the original uses to which the tools were put. This system should, in turn, make progressively more sophisticated statistical and distributional analysis possible.

The Excavations at Barton Ramie were directed by Gordon Willey, William Bullard and John Glass between 1953 and 1957. The site is an arbitrary section of a more or less continuous scatter of small house-mounds which dot the upper terraces of the Belize river for nearly $50 \mathrm{Km}$. from Benque Viejo to Cocos Bank. Interspersed among the numerous house mounds are "plazuela" groupings of mounds around a small raised plaza, an occasional larger mounds usually interpreted as temples. Large ceremonial centers occur to the west $(70 \mathrm{Km}$. to Tikal), north and south. Small ceremonial complexes such as Baking pot (actually two complexes) and Floral Park are located within $5 \mathrm{Km}$. .

The materials discussed herein were unearthed largely during the extensive excavations of house-mounds BR1 and BR123, and the limited exploration of 66 other mounds of varying types and sizes. 
The highly domestic nature of the remains makes them unique in the field of Mayan studies, previous excavations being largely centered around major ceramonial centers with associated caches and monuments. Because of this, the stone tools from Barton Ramie can be expected to relate more closely to agricultural subsistence activities than tools from most other sites. Caution should therefore be exercised in making close comparisons between the functions of the tools discussed here and those from other sites, though homologous functions can be expected in many cases.

The present study is intended to give added data to chronological studies, but considerations of the time factor have not been included

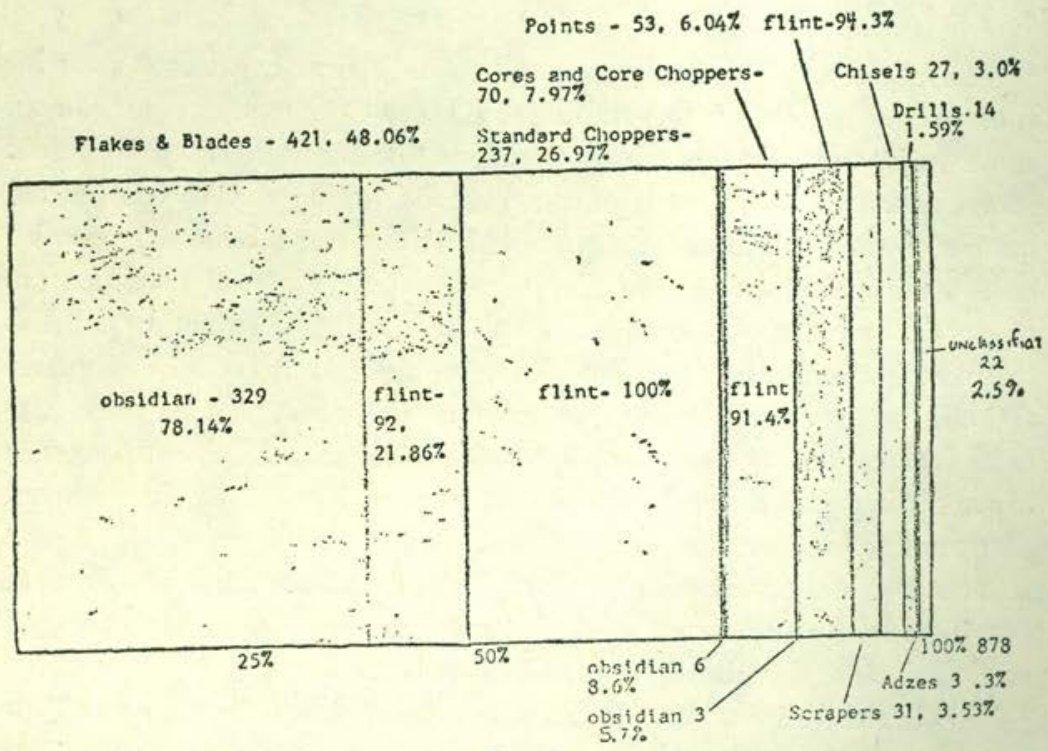

Fig. 1.

here for the sake of brevity. Suffice to say that the tools examined come from all phases recognized at Barton Ramie, from the middle pre-classic Jenney Creek phase to the early post-classic New Town phase. Population peaked at Barton Ramie during the late classic Spanish Lookout phase, and therefore a larger proportion of the tools examined come from this period.

A $15 \mathrm{X}$ steroscopic Microscope, and single 100 watt light source were used for all observations. A translation of a monograph by Seminov, listed in the bibliography was consulted for verification of functional atrributes, though the work he illustrates is entirely European Paleolithic. The kind help of Mr. Ira Berman is 
acknowledged in giving the benefit of his extended experimental work in re-creating observed wear patterns.

Figure one gives a percentage breakdown of the total flint and obsidian assemblage from Barton Ramie. From left to right they are indicated in decreasing percentage values and raw counts. Eccentric flint and obsidian forms have been excluded from the total, though other tools listed in the original report as "ceremonial" have been included because of the general unclarity and variability of that term. (Fig. 1).
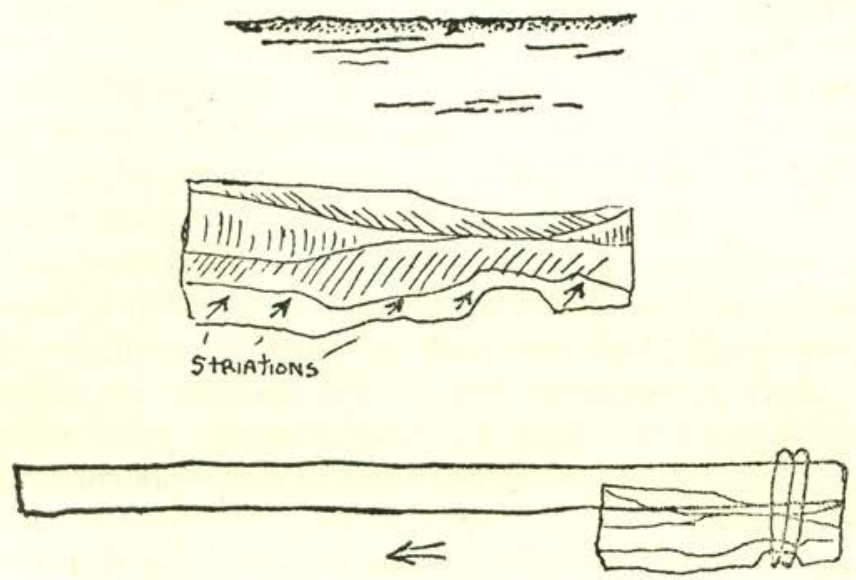

Figs. 2, 3, 3a.

As can be seen, obsidian and flint blades are the most common artifact, composing $48.06 \%$ of the total assemblage. This is the case at most sites in Mesoamerica, and these tools are generally considered to be utility knives used when needed for a wide variety of functions. As we shall see, evidence from wear patterns indicates that they were indeed used for at least several different jobs, though once a tool was used in a specific way it tended to be used only that way afterwards. If this were not the case we would find several different kinds of wear on a single blade.

Due to the Mayan custom of preserving especially fine blades unused in caches and burials, and the modern museologist's tendency to preserve only the most perfect specimens, a large portion of the obsidian blades examined were unused and showed only wear associated with deposition and burial for long periods.

Four obsidian blades examined showed visible use-marks discer- 
nable from the natural striations of the material. These marks take the form of dull scratches in an otherwise shiny surface, caused by friction with small hard particles (probably sand) which were embedded in the material being worked. The first specimen, catalog $\mathrm{n}^{\circ}$. 822, was $5.1 \mathrm{~cm}$. in length and about $1.5 \mathrm{~cm}$. in width, placing it in the larger size range distinguished by Willey. The blade had one sharp edge which was extensively worn, having a granular appearance suggesting use againts a very hard material. All wear striations ran parallel to the blade edge (Fig. 2), indicating that the blade was used in a back-and-forth sawing motion which penetrated deeply. The blade did not have any mounting notch, and was not subsequently used for another purpose.

No other specimen was observed to have this type of wear, and it represents a specialized cutting tool used on hard materials such as bone, shell, or soft limestone. The next blade examined also constitutes a type of it's own. Blade no 525 (Fig. 3) has one fairly deep, blunted notch near the striking platform. While notched blades were not common at Barton Ramie, they are reported in large numbers from other Maya sites such as Altar de Sacrificios (Willey, 1972) where aproximately $34 \%$ of the complete obsidian blades were notched. These notches almost definately relate to hafting, and the single and double-notched varieties may represent alternative modes of hafting.

In this specimen, the notched side is worn, and the other side shows no wear at all, as would be expected if the notch were used to bind the blade to a haft which ran along the other edge. The wear pattern is angled diagonally towards the notched end, suggesting that the tool was pulled towards the body while slicing downwards through a fairly soft material. Figure $3^{a}$ represents a probable reconstruction of hafting and mode of use.

Two fragments of the slender, lancet variety of blade were examined. They showed wear striations parallel to one edge only, and though there is no notching or other hafting mark, tools this small were probably held in some manner for the ligth slicing work they were used for. No specimens of the more common doublenotched blade were available for examination, and we must reserve judgment on how these implements were used. The possibility exists that there were many more varieties of blades present which were not available at time of this study.

It should be emphasized that nicking alone on the edge of an obsidian blade does not constitute evidence for useage. Nicks of 
this kind can be caused by many different agents in the production, handling deposition, and preservation of the artifact.

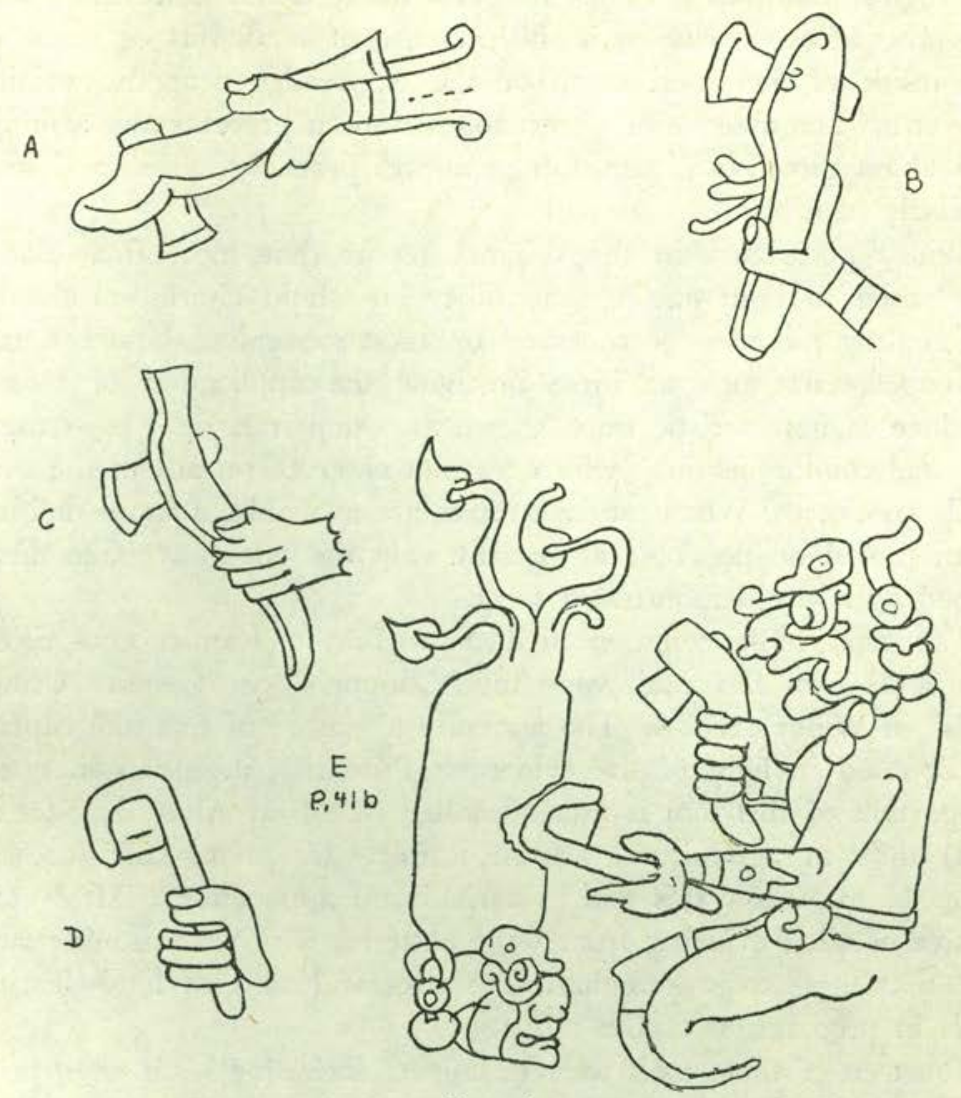

Fig. 4.

We must conclude that any complete analysis of obsidian blades must be based on a larger sample than was available here. Nevertheless, two, or probably three modes of use have been isolated, and in the future we can expect to isolate complexes of size, notching, and wear patterns which will allow separation in the field into several truly functional categories. Flint blades constituted $21.8 \%$ of the blades excavated, and three specimens were examined microscopically. Results were dissapointing however, for the granular nature of the chert-like flint obscured most striations that may have been present.

Blade $n^{\circ} .1100$ proved interesting nevertheless, for in many ways it was identical to the second obsidian blade mentioned, and may 
have been hafted in the same way. Again, one side of this blade shows extensive wear, consisting of a blunting of all high ridges and the slightly undulating edge. The other edge is still quite sharp and unworn. Most convincing is the presence of small bits of black on the inside of the small notch on the worn edge near the striking platform. The absence of discernable striations prevents any assumption about direction of use, though it was probably hafted and used similarly to $\mathrm{n}^{9} 525$.

Willey postulated in the original report that most flint blades were used in light cutting and other household chores, producing the slightly nicked edge observed on most examples. Under a microscope, tasks such as these involving the application of torque produce a characteristic trace known as a step fracture, (I. Berman, personal communication) which was not observed on any of the available specimens. When larger samples are available, a more definite opinion will be possible; at present only the one flint flake mentioned had any demonstrable wear.

The next most common artifact at Barton Ramie, comprising almost $27 \%$ of the total, were the "Choppers" or "General Utility tools" of Willey's report. The agricultural nature of this tool cannot be doubted in light of the evidence. Primarily, in urban sites the proportion of this tool is much smaller $(8.2 \%$ at Altar de Sacrificios) than at agricultural Barton Ramie. Dipictions from codices (Fig. 4) also show this tool in agricultural applications. Most conclusive of all is evidence from wear patterns, which consistently suggest that these tools were hafted as axes and used as land-clearing tools in preparation of the milpa.

Fourteen of these tools were examined, including what were originally classified as Standard Choppers and Chopper-Pounders. Polls were examined for pounding, bits were checked for direction and depth of wear, and the mid-sections of the tools were checked for wear with a haft. The tools clustered into three categories by morphological characteristics and wear patterns. These categories overlap the original types listed by Willey to some extend, and include some of what were originally classified as Large, Bifacial Adzes or Planes.

The most common type of chopper exhibits a consistent set of key attributes, though it varies in shape from broad teardrop; pointed poll to elongate; square poll, with variation between. Size varies from 12.6-17.8 cm. in length among the specimins examined, and chipping quality ranges from rough to very fine. Plates 1,2 , and 3 illustrate the range of variation. 
The diagnostic attributes are illustrated in figures 5 and 6 , and are listed as follows:

1. A distinct wear pattern, the striations of which go diagonally across the blade in the same direction on either side (Figs. 5 \& 6). Indicated by $\rightarrow$ in fig. $5 \& 6$, they are sometimes barely discernable on
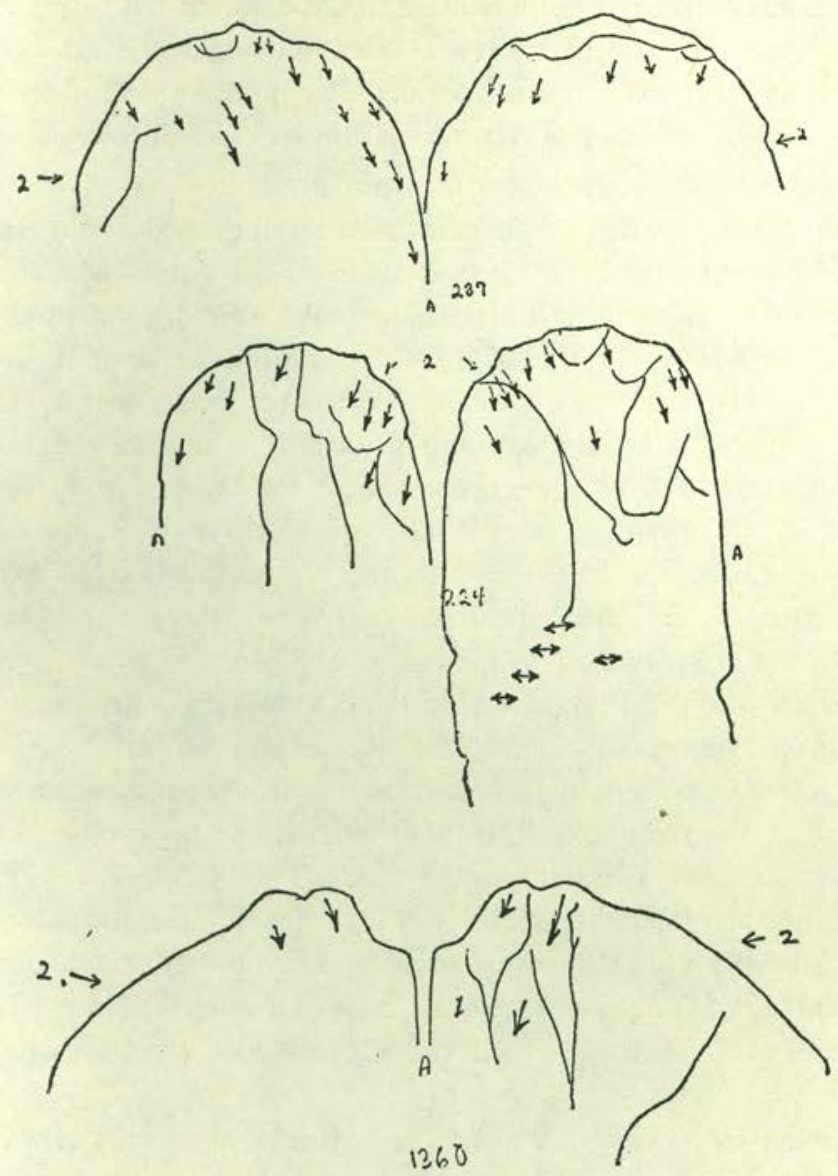

Fig. 5

grainy chert implements, and are sometimes accompanied by a high polish.

2. Battering and often fracturing of the blade at it's bottom edge, at the point from which the stirations originate. Indicated by $2 \rightarrow$ on illustrations. 
3. Single or double notches for hafting, situated at the top of the blade in aproximately the direction the striations point. This edge is marked $\mathrm{A}$ in the illustrations. These notches are not always present, and are sometimes very small, or replaced by a single deep notch on the bottom edge. Teardrop and arc-chaped blades do not usually have either.

4. Polishing from friction with a handle, often occuring only on the more convex side of the tool, takes the form of non-directional grinding or transverse striations on the prominente ridges of the middle-secction of the tool, represented by $\leftrightarrow$ in illustrations.

5. A curved bit edge, often unworn on top.

These attributes are explained best by the model illustrated in Fig. 7. Because the implement is swung in a circle over the head, the striations follow this curve diagonally over the surface of the blade. The bottom of the blade often shatters because it takes the impact of most blows. Notches are neccesary on narrower blades to provide a grip to hold them into a handle, which rubs againts the blade in at least two directions during the swing producing wear on the tool. The cutting edge itself must be curved to allow different angles of stroke. Variations in size and shape can best be explained on the basis of each user's personal preference, though the possibility exists that shapes tended to change over time.

In many ways this model is similar to the tools in Fig. 4 from the codices, though the tools seem to be hafted differently. The Codex forms also seem slightly smaller, and may approximate a hatchet rather than an axe. The odd wrench-like tool represented in Fig. 4 is depicted cutting down a tree (Thompson, 1872), a function upon factors of time and distance to explain the absence of such a tool from the Barton Ramie assemblage. It should be noted that a haft such as illusatrated in the codex Dresden would not produce the pattern of wear observed on the body of the Barton Ramie specimens.

Chopping tools which do not fit in with our above list of attributes are in a minority at Barton Ramie, and some of them are listed by Willey as Chopper-Pounders. These tools exhibit extreme battering of the edges, and are most likely (as Willey suggests) standard choppers which were broken and subsequently re-used as hammers. One specimen clasified originally as a Chopper Pounder however, $n^{\circ}$. 2076 shows all the attributes to be expected from a wedge used for splitting logs into boards. The heavily battered poll, striations over most of the tool's body, and wear marks that are at $90^{\circ}$ to the 
tool's bit rather tham at a diagonal are all diagnostics of this tool. In ligth of the evidence for the use of split logs and boards in house constuction at Barton Ramie '(Willey, 1965, p. 515), an artifact classified as a wedge is conspicuously lackin from the total assemblage. It is possible that some implements classed as ordinary choppers are such a tool, though it is also possible that the ground-stone celts
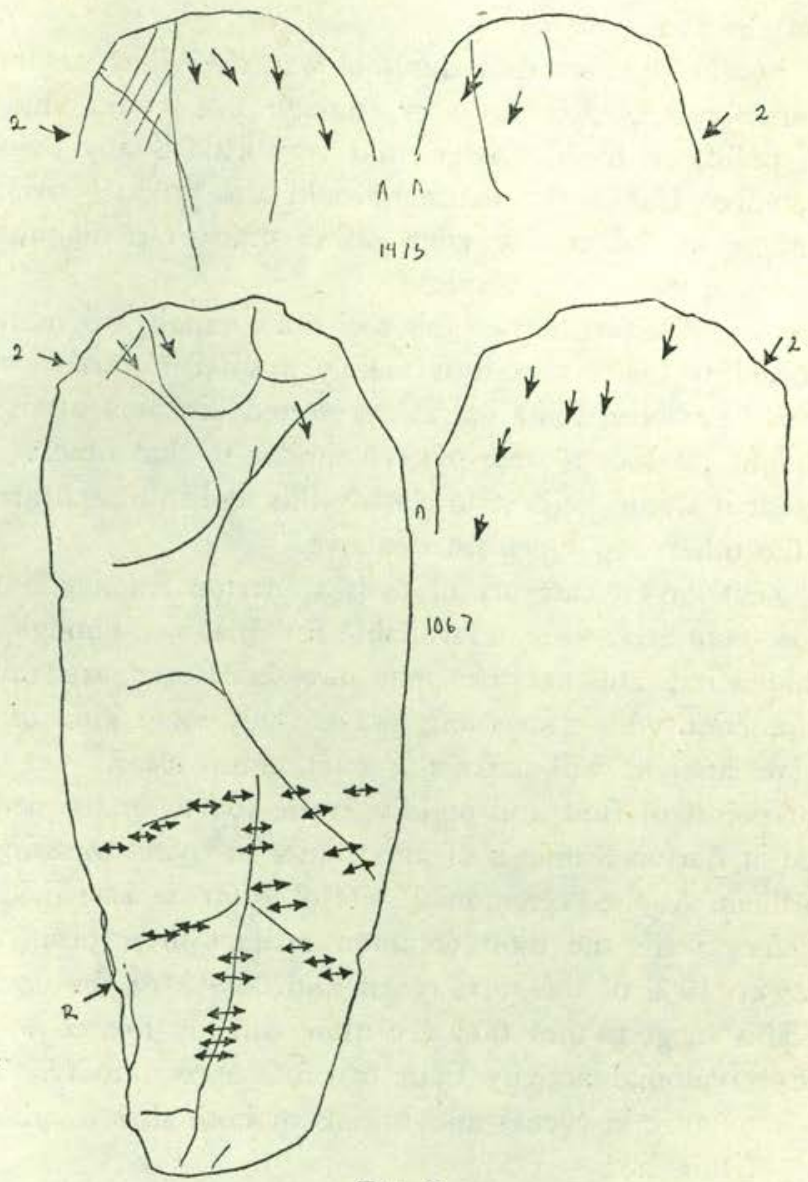

Fig. 6 .

which often have battered polls filled this function. A definite conclusion will have to wait until these celts are examined.

Another type of chopping tool, classified alternately by Willey as Adzes or Planes; Bifacial, Large or as Standard Choppers, has $a$ wear pattern distinct from that of the common axes described above. They are characterized by a straight cutting edge, a generally more 
plano-convex cross section, with more wear on the flatter edge, and are generally of smaller size than standard axes (10.1-12.7 cm. in length) (Plate 3a.). Their wear patterns are not readily explicable, as in all three specimens noted the patterns ran slightly diagonal on one side, and slightly diagonal in the opposite direction on the other side as shown in figure 8. This is the opposite of the standard axes, on which the striations run in the same direction on both sides of the tool.

The possibility exists that this tool was, as Willey suggests, hafted transversly and used as an adze, though this would tend to leave a high polish on the flat edge, and very little if any polish on the convex edge. Use in this manner would also produce striations at a right angle to the cutting edge rather than at a diagonal, as the tool is swung in a single plane.

At present the function of this tool must remain enigmatic, though the possibility exists that it is merely a smaller variety of standar axe which has been re-hafted in a reversed direction after some use. This might produce a wear-pattern similar to that observed, though at present it would be best to classify this tool in a separate category from the other two types listed above.

The next largest category of tools at Barton Ramie, that of cores and core-pounders, were unavailable for analysis. Though their size and shapes indicate that they may have been used as hammerstones in conjunction with chisels and gouges, only some kind of statistical co-variate analysis will make this relationship clear.

That points of flint and obsidian were fourth in frequency of occurence at Barton Ramie is of importance in trying to assing a function to them. At the "ceremonial" site of Altar de Sacrificios (Willey, 1972) they were the most common artifact after obsidian blades, making up $19 \%$ of the total count and $53.3 \%$ of the counted flint tools. This suggests that they are more directly related to what are termed ceremonial activity than to subsistence activity. That they occur frequently in caches and burials at both sites is added confirmation of this fact.

Seven specimens of three varieties, all of flint, were subjects of micro-analysis. The main intent of this analysis was to settle the long standing confusion over whether these artifacts were used as points or as knives.

Plate 4 illustrates a variety of what are termed Unstemmed Bifacial Points or Knives; delicate. Otherwise known as laurel-leaves, three specimens were examined $\left(n^{\circ} .76,700,1971\right)$ ranging in length 
from 11.4 to $19 \mathrm{~cm}$. All three lacked any attributes which could confirm their use as knives, such as step-fractures, edge striations parallel to the edge, or wearing down of sharp ridges near the edge.
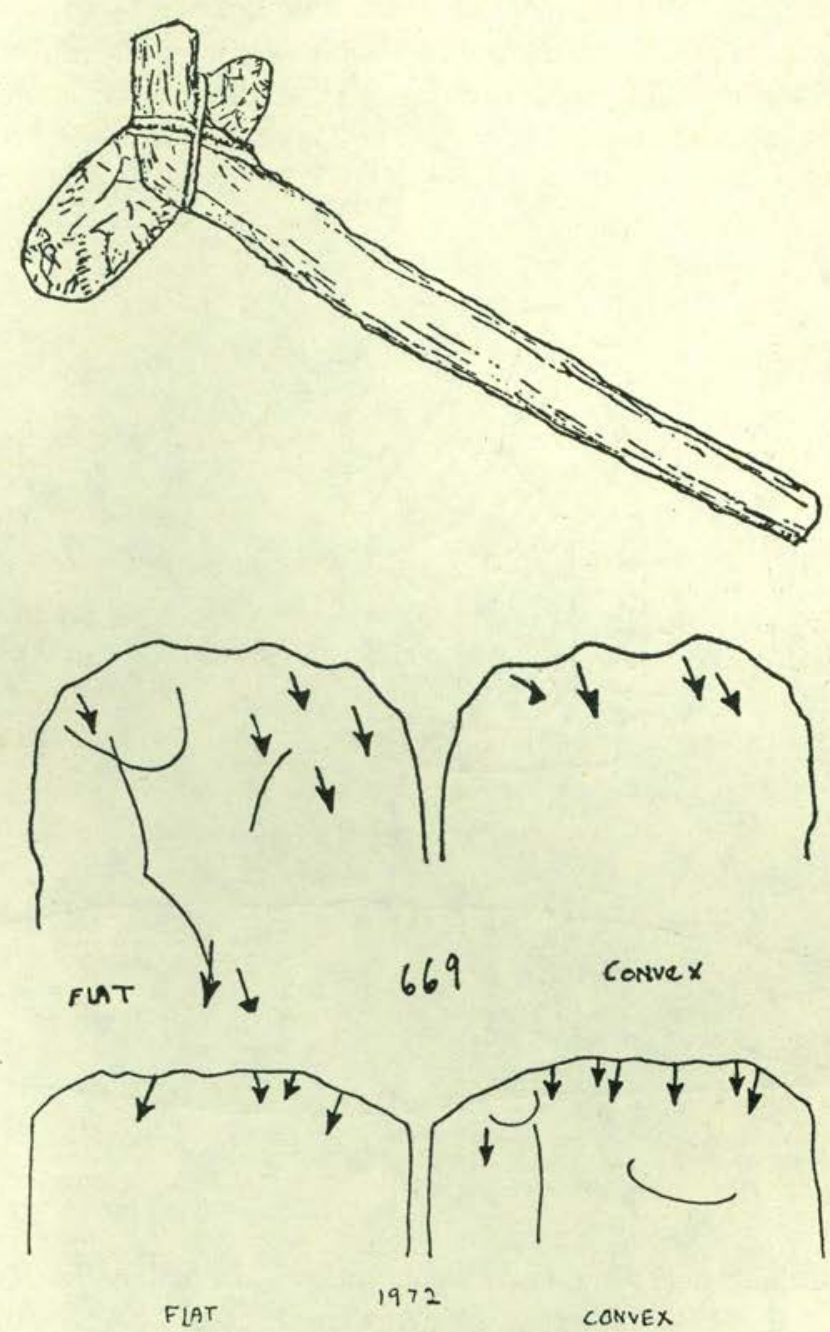

Fios. 7 y 8.

On the contrary, all three specimens had point ends broken off, and a very slight dulling close to the broken tip-attributes to be espected from a spear or lance point. This does not rule out the possibility of use as a "ceremonial" knife, though that exp'anation 
does not explain the high proportion of specimens with broken tips among those illustrated by Willey.

Three specimens of the Tapered Stem; Long Blade variety of bifacial point-knife $\left(n^{\circ} .75,3090,1948\right.$, plate 5$)$ were also seen, ranging in length from 11.4 to $15.2 \mathrm{~cm}$. . The heavier, less well-obinned specimen $\left(\mathrm{n}^{\circ} .3090\right)$ did appear to have significantly dulled edges, though the granular nature of the flint made positive identification difficult, and obscured any pattern. The other two specimens had
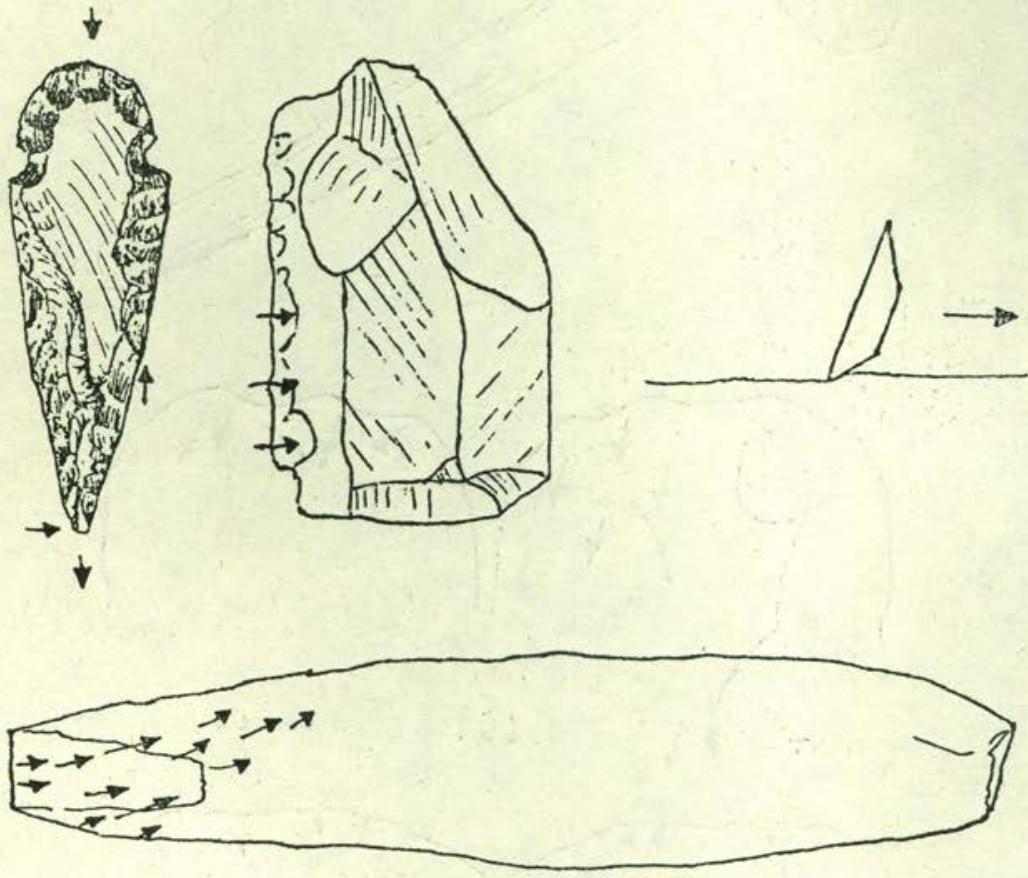

Figs. 9, 10, 10a y 11

slight dulling near the point and no other discernable characteristics. Again, all three specimens points were broken off. Obviously, no conclusion was reached on whether there was a difference in function between these implements and the unstemmed variety.

In light of the fact that neither variety showed attributes expectable in a knife, and that both varieties often occur with broken points, we would tentatively classify both varieties as spear-point. That all varieties occur in both roughly and finely chipped forms 


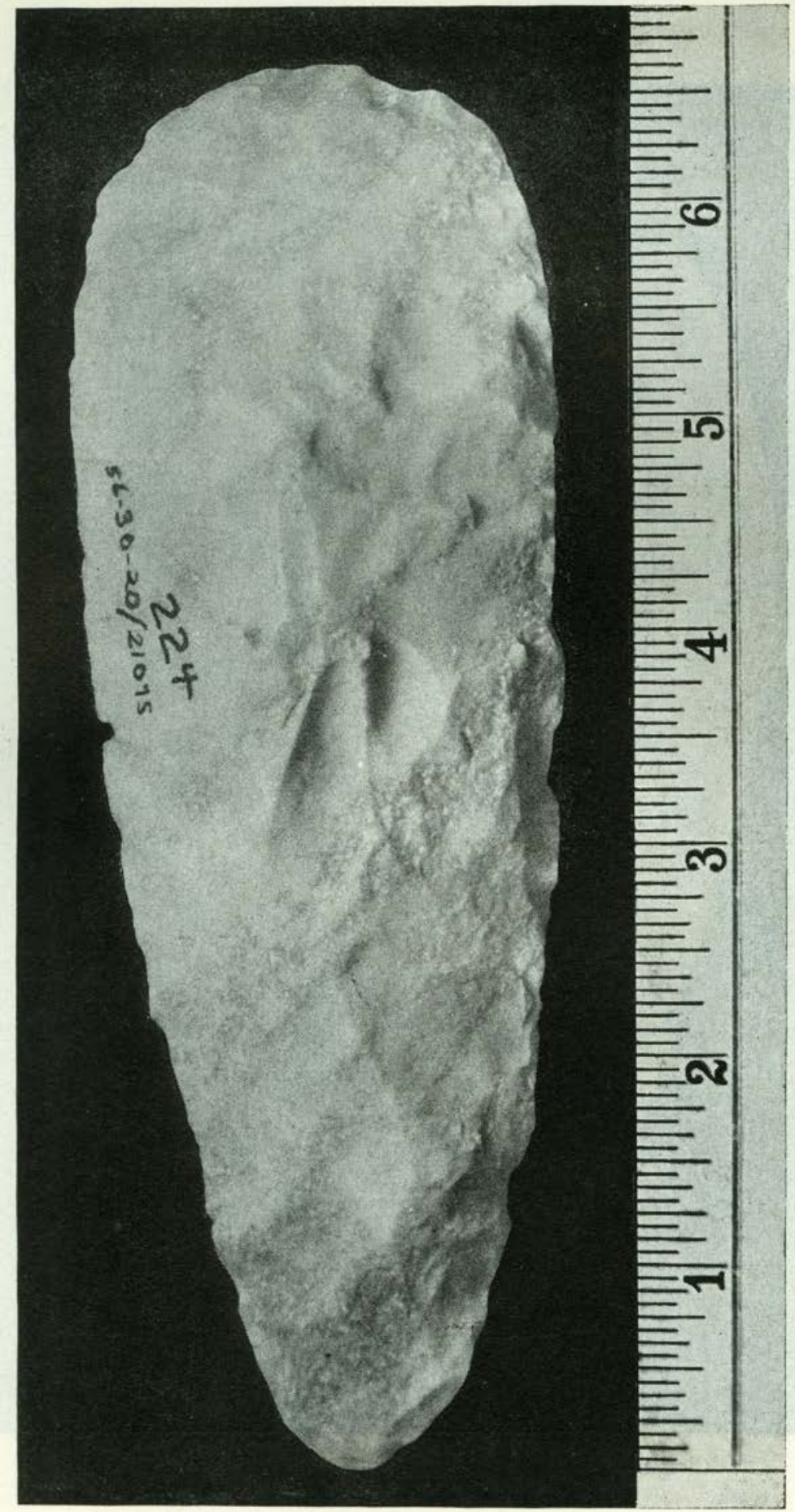

EsFisduirdsokedeuthulitan MayayaV dV.OK,X,97ø76/7

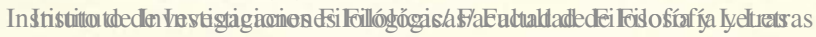

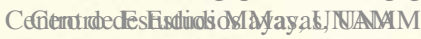




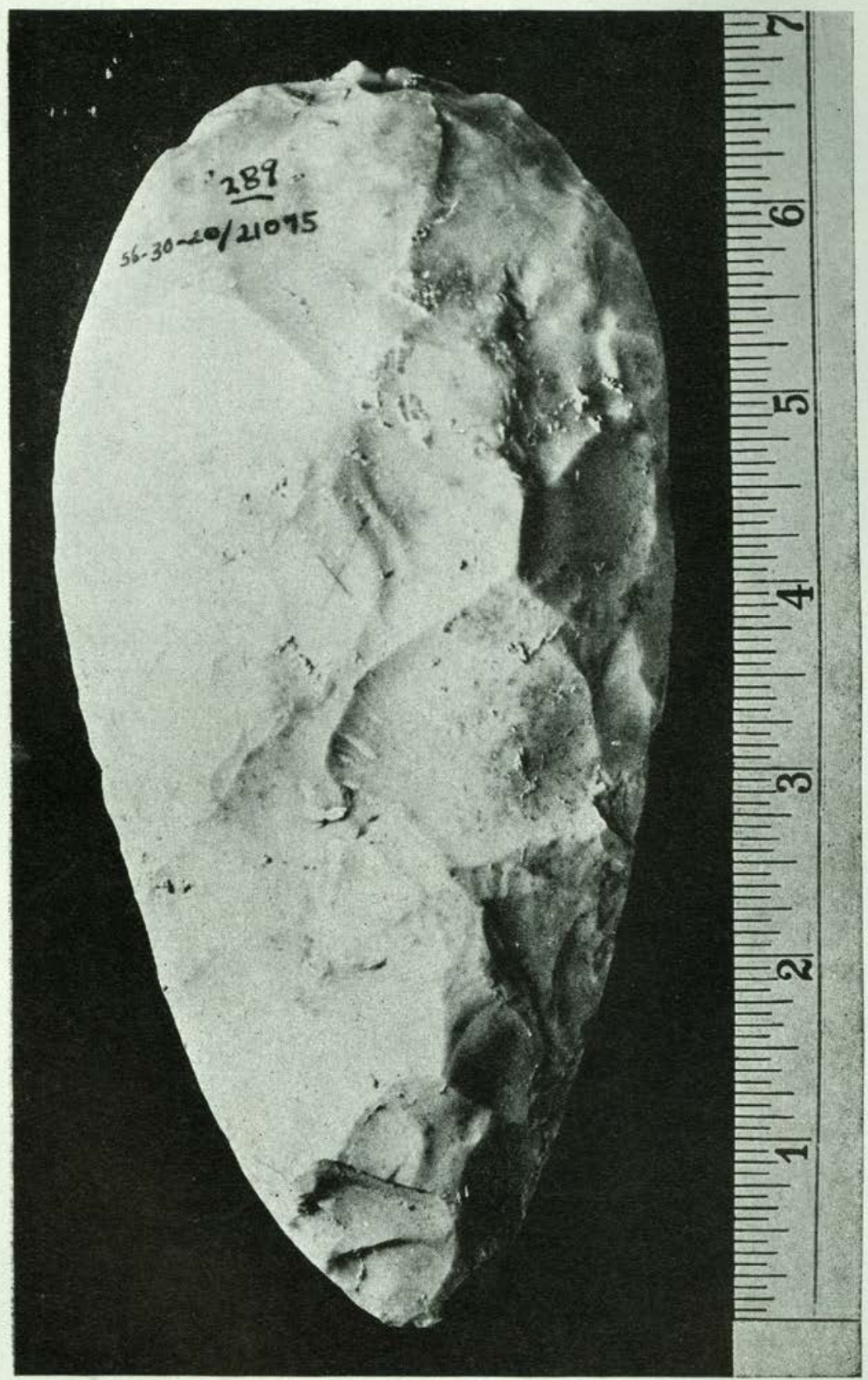

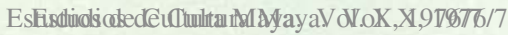

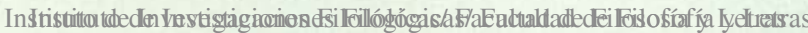

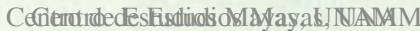




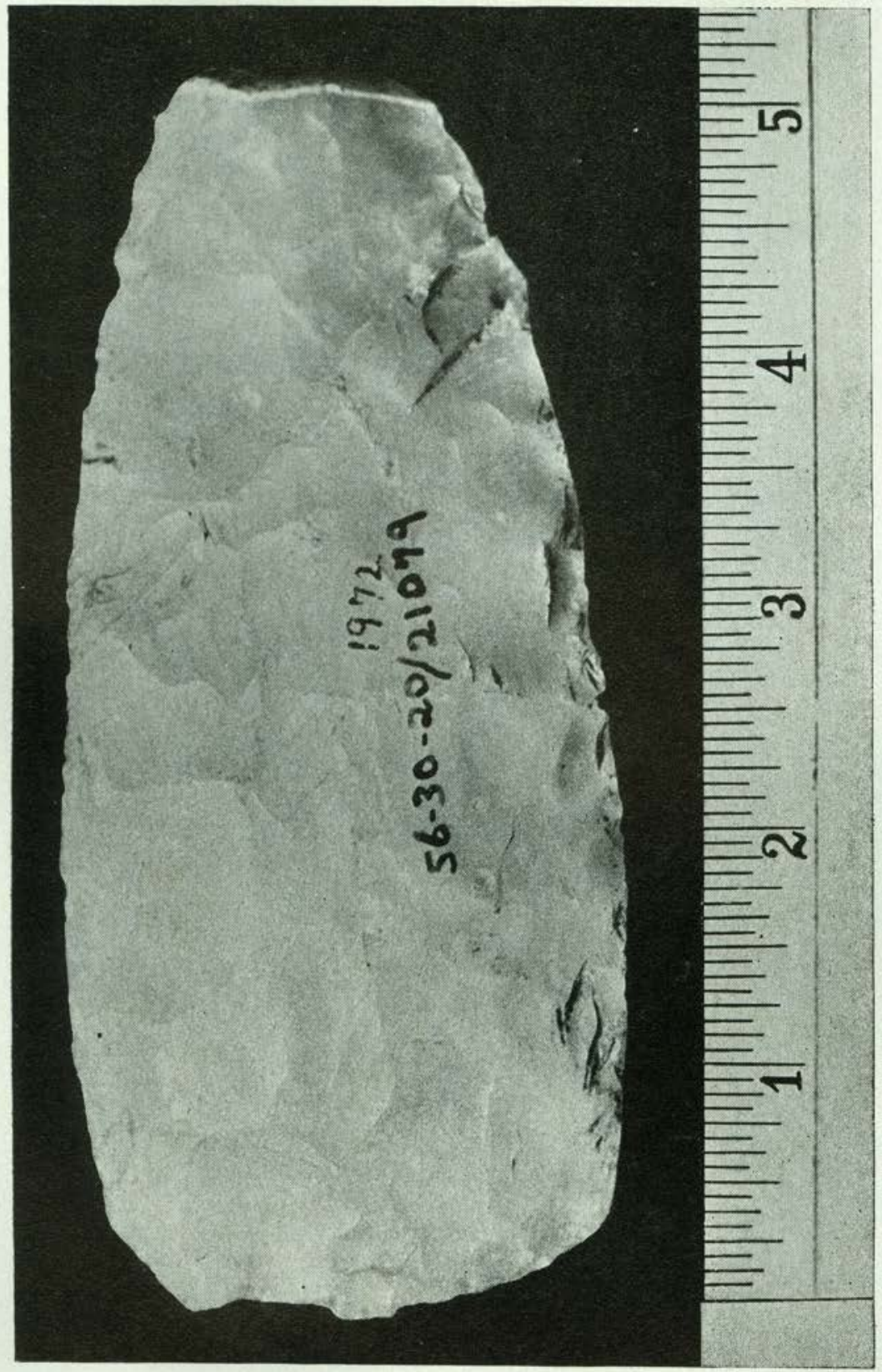

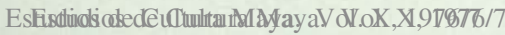

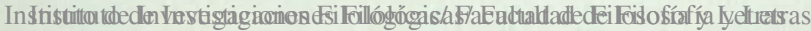

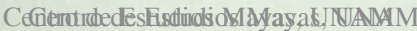




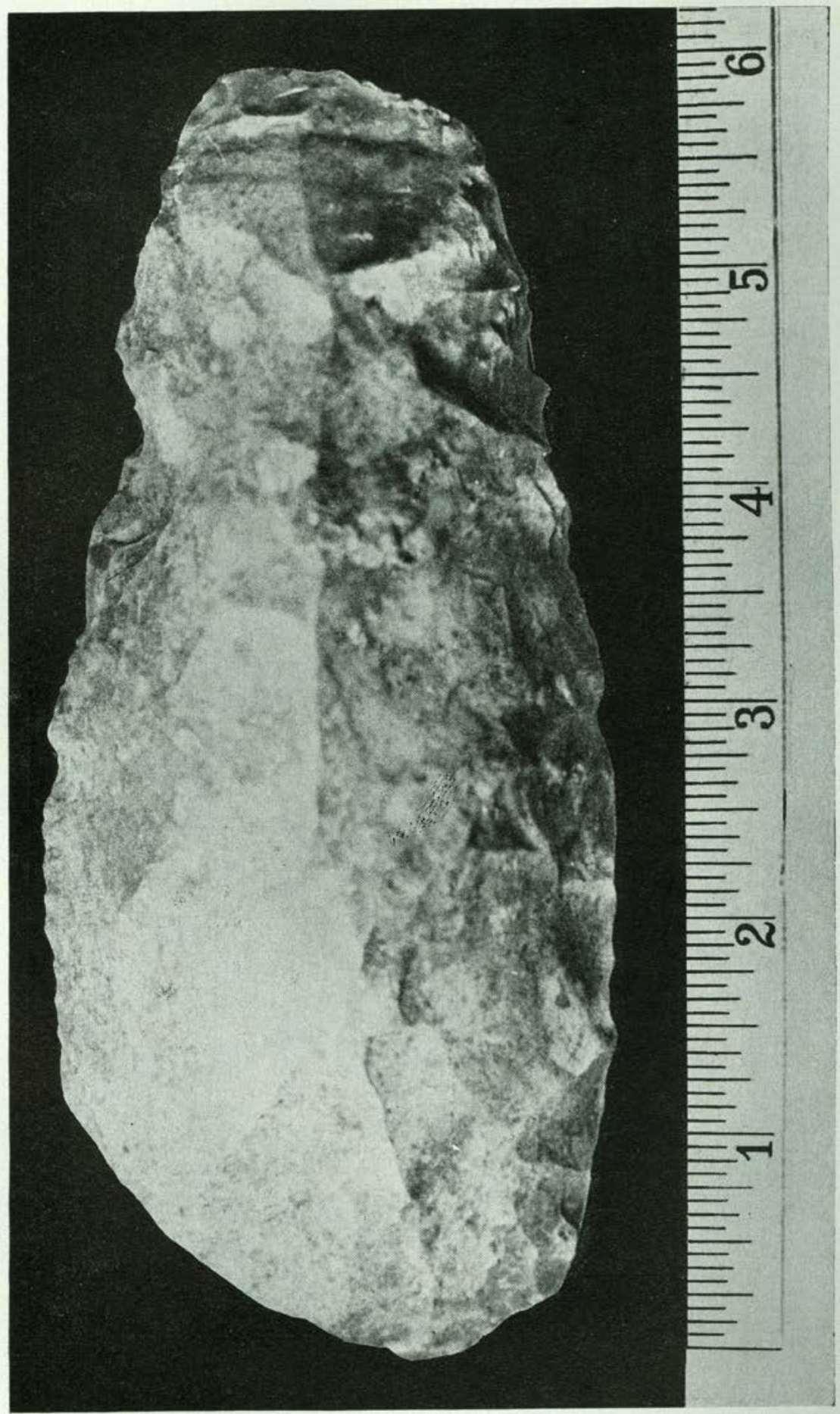

EsFisduiolickedetOtultan MayayaV ol.oX,X,97676/7

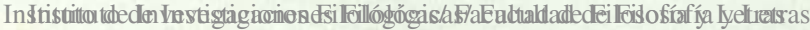
CefutrotrdedesFisduidioMIAYasab,INANAM 


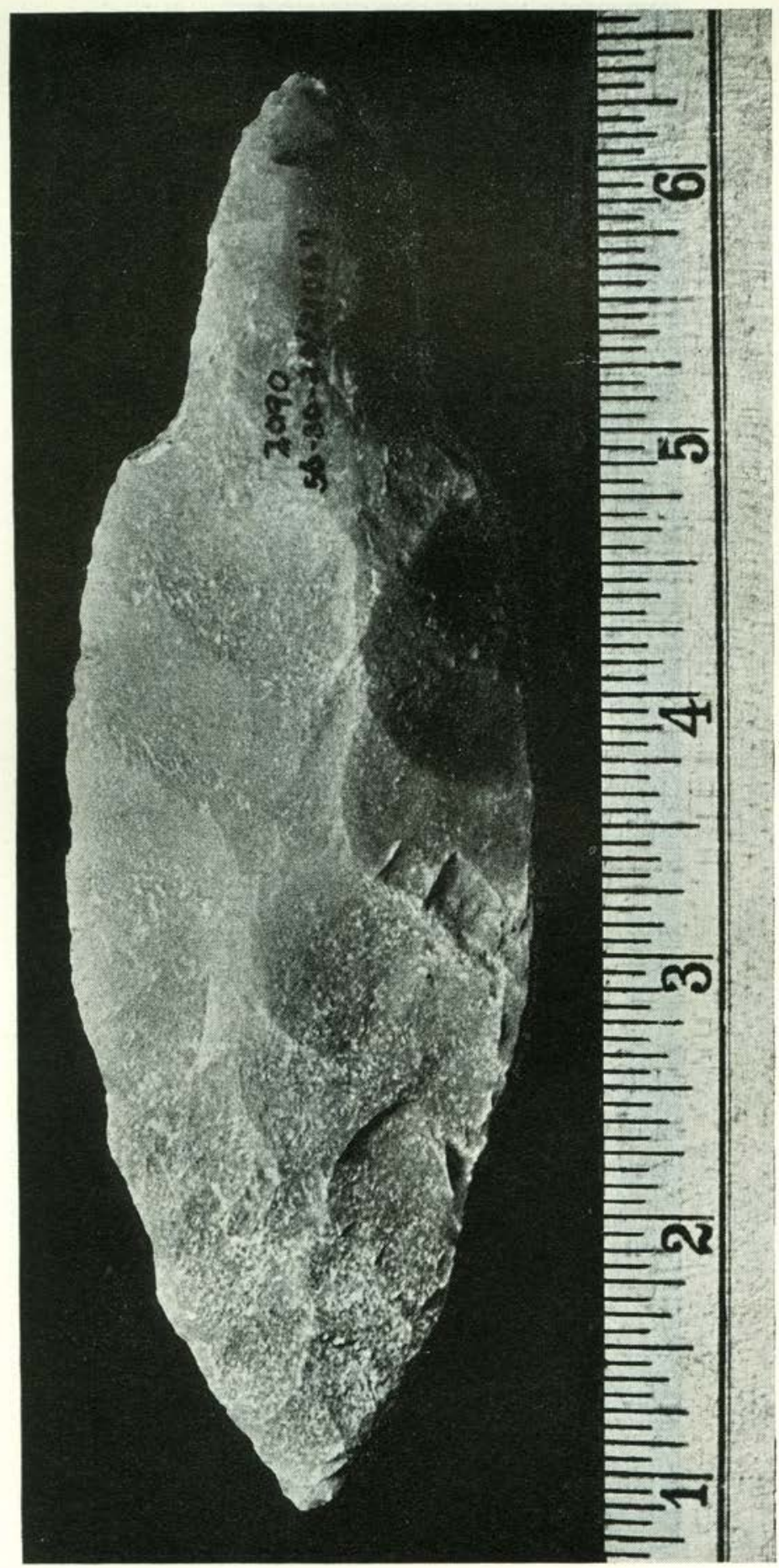

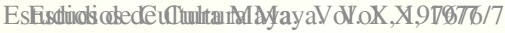

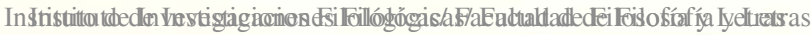

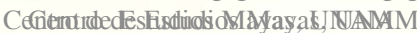




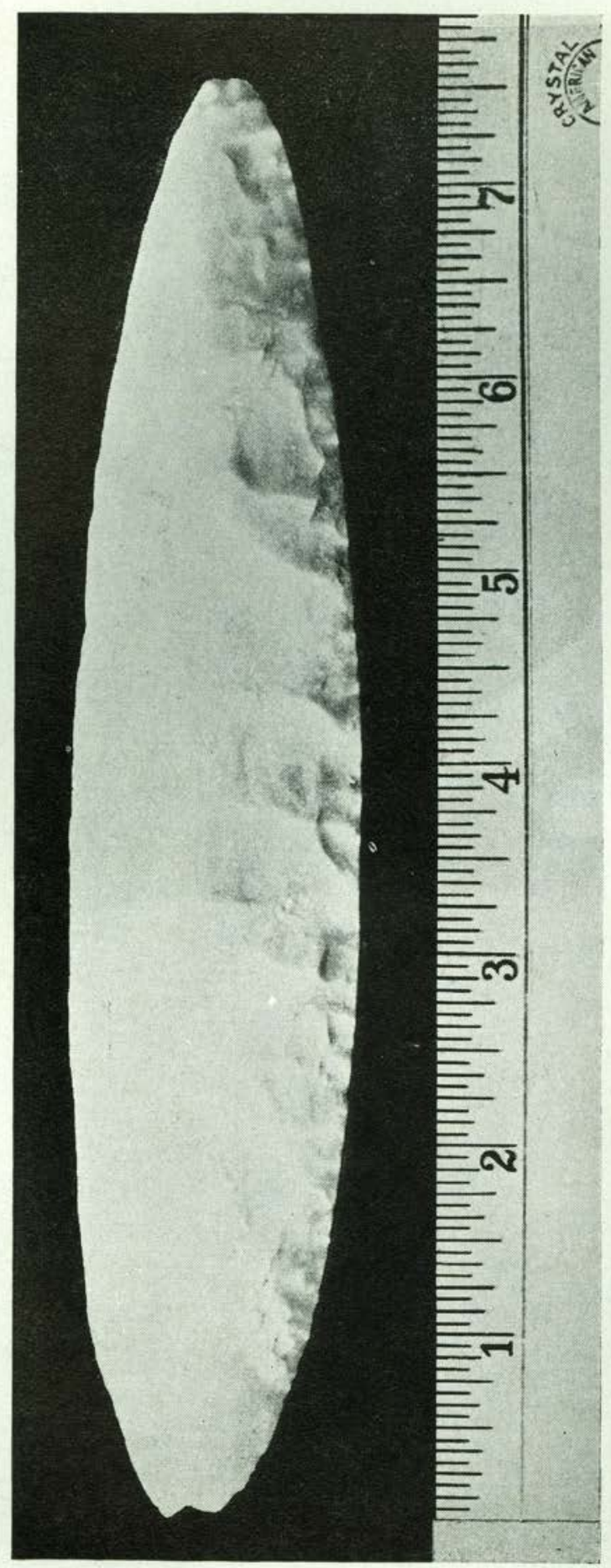

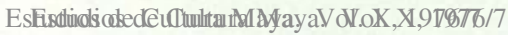

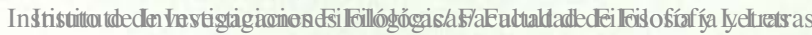

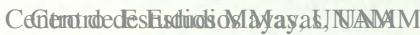




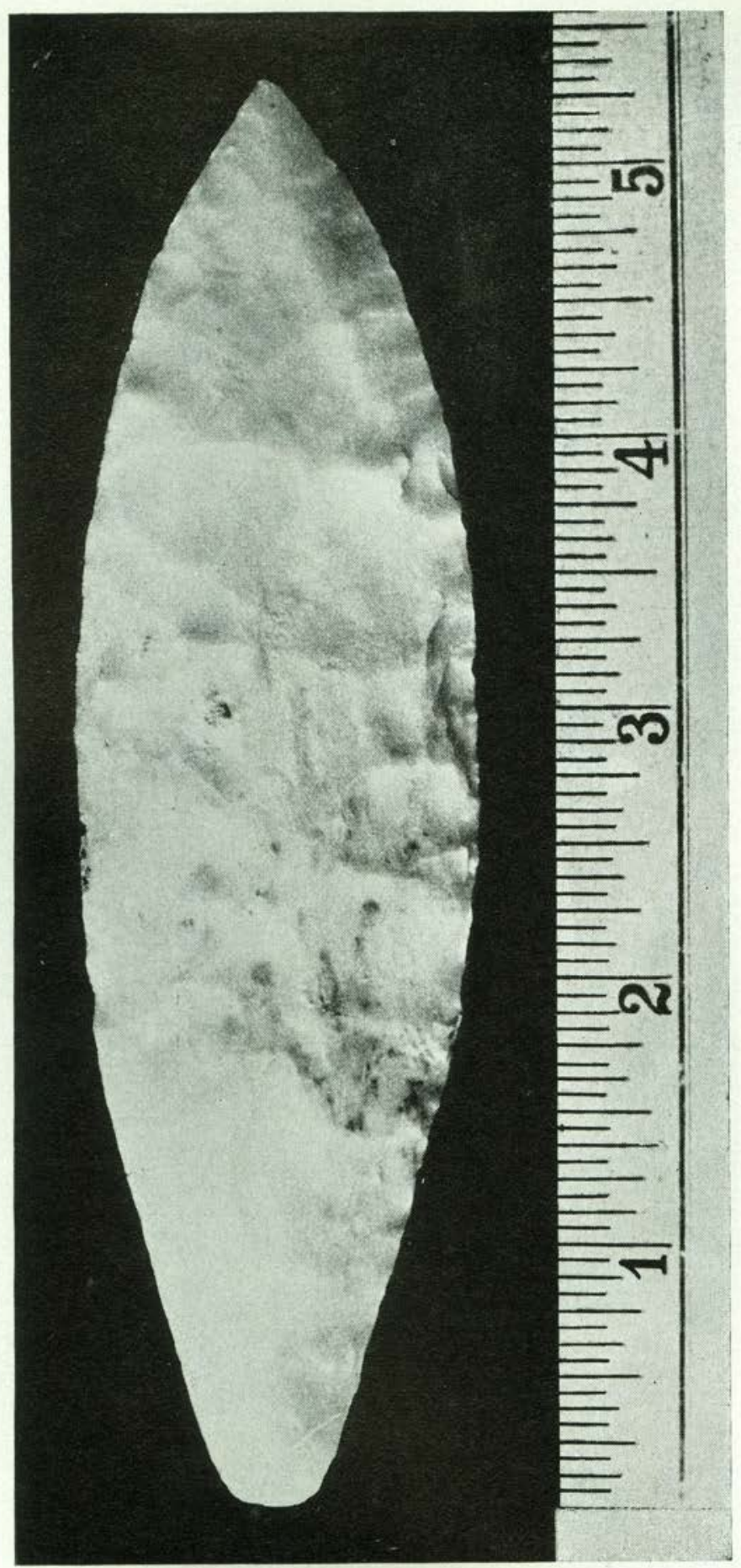

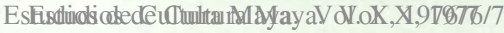

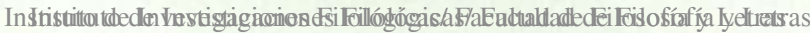

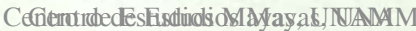




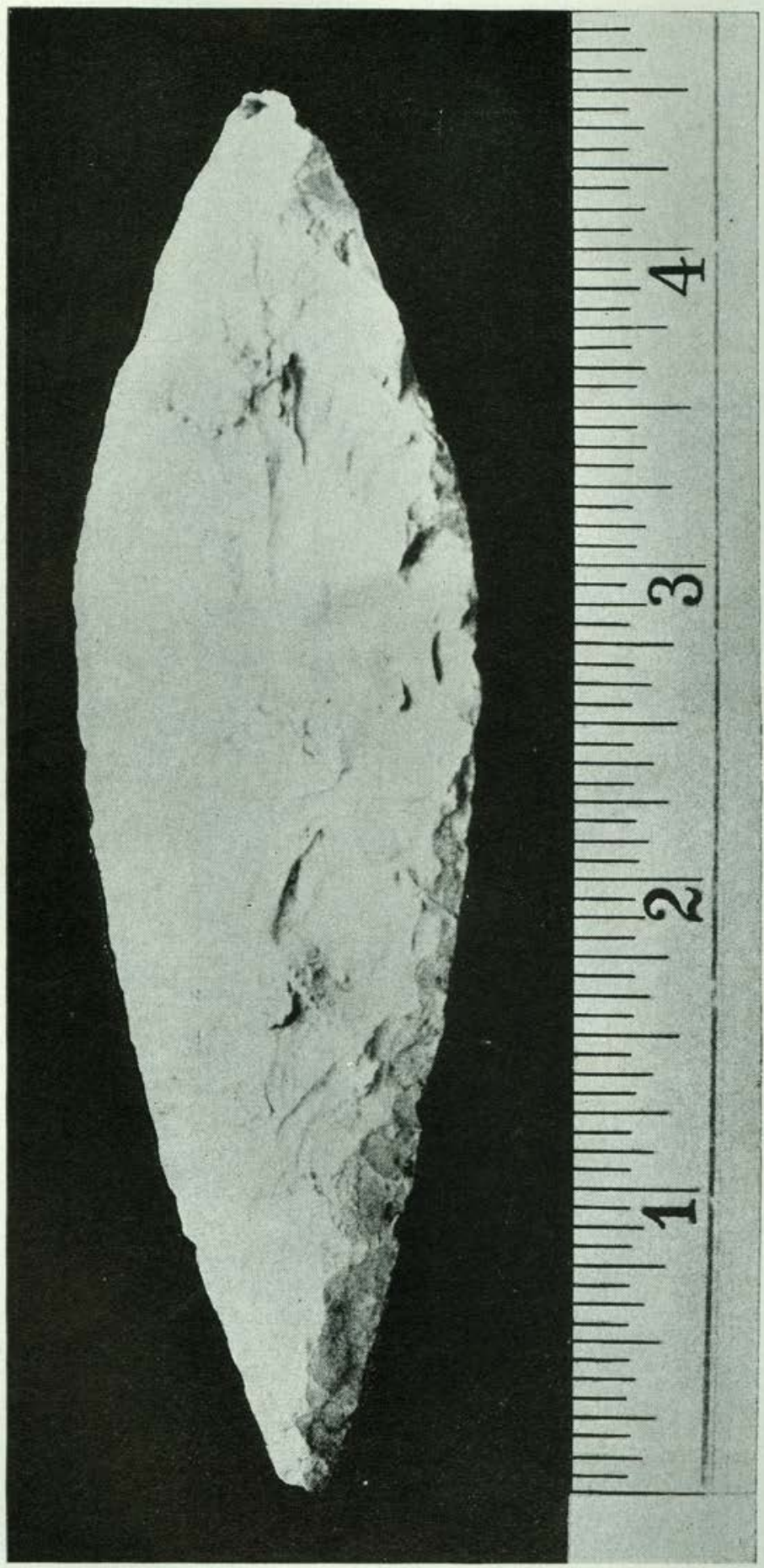

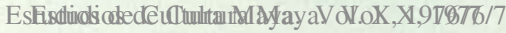

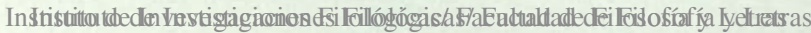

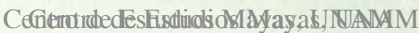




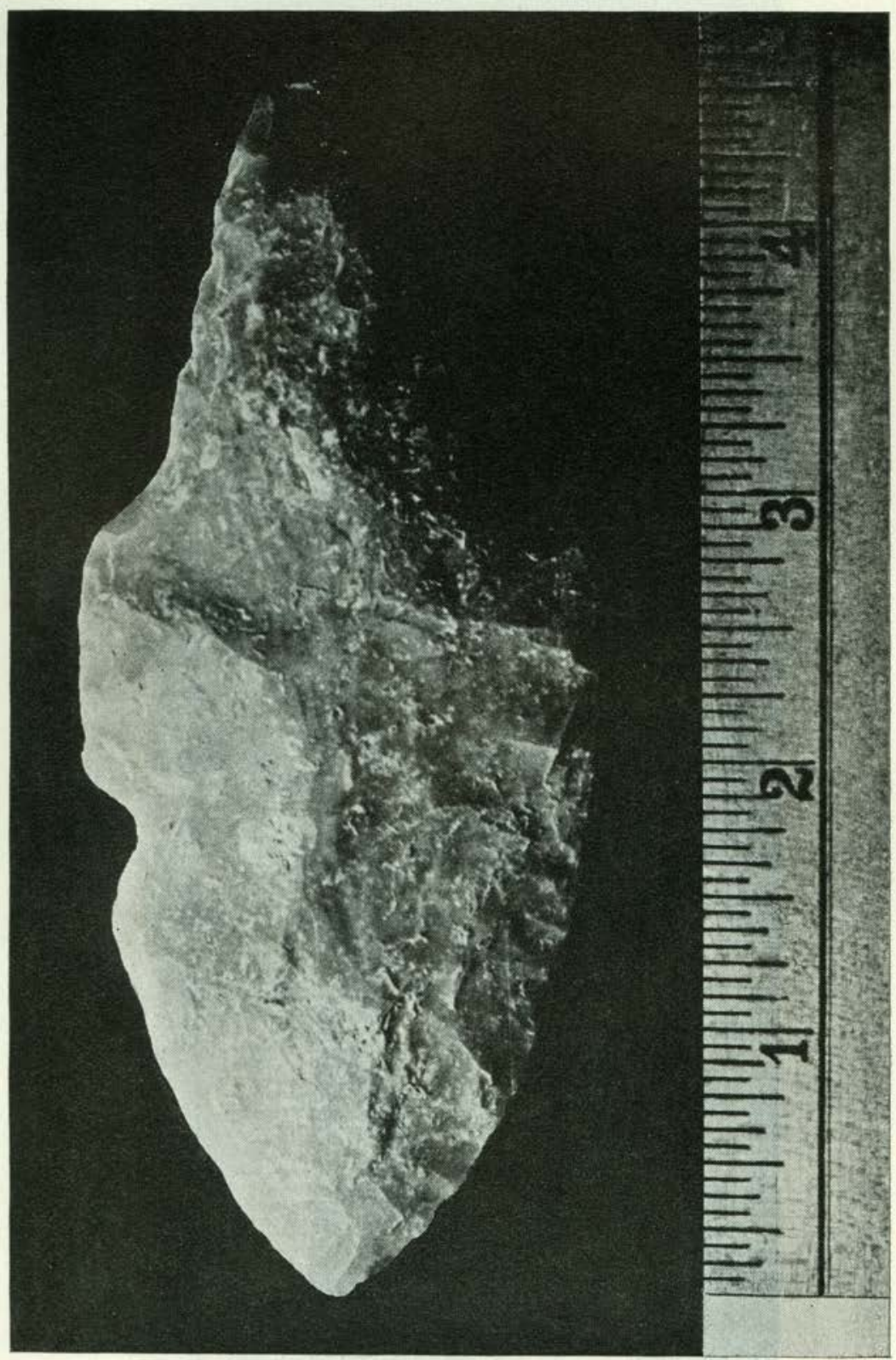

EsFisduioliokedeuTumitan idayayaV dV.OX,X,97676/7

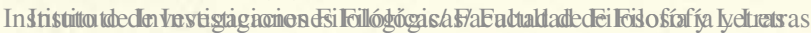

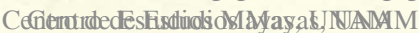




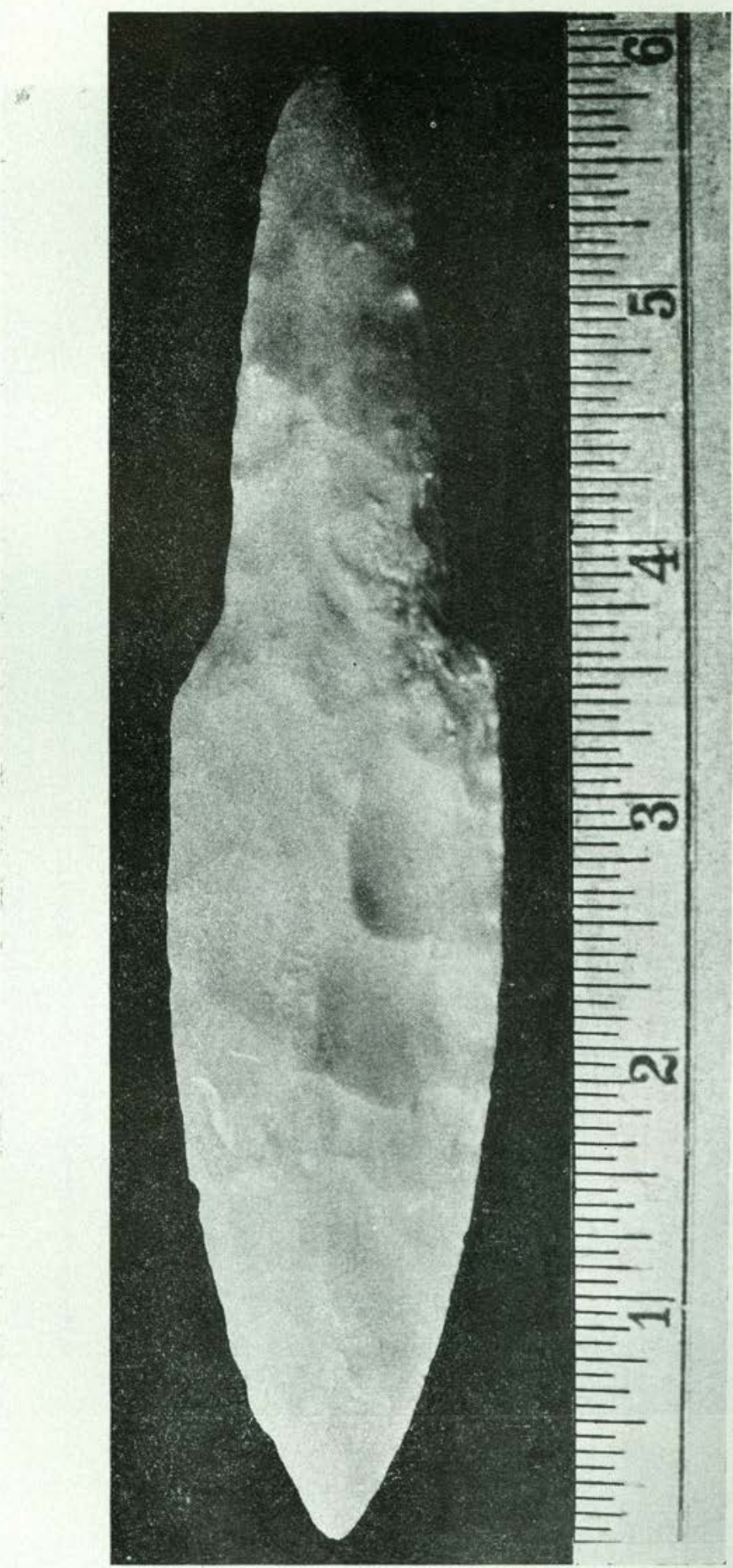

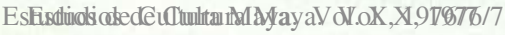

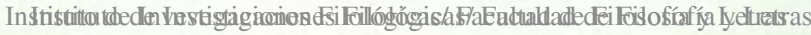

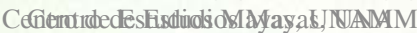


can best be explained by using Willey's original categories of utilitarian and ceremonial. The coarse, poorly-chipped variety was probably used for hunting game, while the finely chipped varieties were reserved for ceremonialism, warfare, or both. Statistical studies may throw more light on this hypothesis in the future.

One other point was examined (Fig. 9), which, due to size belongs in a separate class. This artifact ( $N$. 681) is a mere $4.4 \mathrm{~cm}$. in length, and belongs to the Notched Bifacial Point; Double Side Notch variety. That this was a projectile point can scarcely be doubted. Small bits of black resin cling to the insides of the notches, and minute striations run in a direction parallel to the axis of the point. In general the edges were unworn, and a slight breakage of the point was observed, all characteristics of points in general. These tools were quite uncommon at Barton Ramie, only four specimens being recovered. This is what we would expect from a group of people that were largely agricultural.

Specimens of the remaining point forms at Barton Ramie, including the impressive stemmed Plano Convex variety, were unavilable for analysis, though they have been tentatively classified as spearpoints on the basis of morphological information.

Scrapers were the next most common artifact at Barton Ramie, comprising $3.53 \%$ of the total number. Examining a large number of these artiface was important due to the highly nonstandardized nature of their form. For this reason there are no uses proposed here for this type of tool based on the evidence from the three tools examined. We will however describe two of these tools and discuss them as individual cases.

Prismatic Side Scraper n'. 937 (Fig. 10) showed a high polish on a small portion of the convex side. As the striations there ran at 90 . to the blade edge, and the flat edge was completely unworn, we can confirm that this tiny implement was used as a scraper. It was probably used on vegetal materials, resulting in the absorption of silica and a glossy, varnished-looking surface. Mode of use and direction of movement are indicated in Fig. 10a.

Prismatic Side Scraper $n^{\circ}$ 1041, showed a puzzling pattern of diagonal striations on only one of the many facets of it's convex side. The only thing that can be said with surety about this tool is that it is quite difrerent from the one previously discussed, though outwardly similar. It probably had a very specialized use, confirming our assumpitions that these were generaly non standardized tools. 
Gouges and chisels were comparatively common artifacts at Barton Ramie, comprising $3 \%$ of the total. As these tools were almost surely used for wood-working, we have a hint here that the Maya used wood in many ways that we know little about at present. At Barton Ramie these tools are characterized by the following attributes:

1. A transversal cutting edge formed by the removal of one deep flake from the top of the tool, leaving a channel.
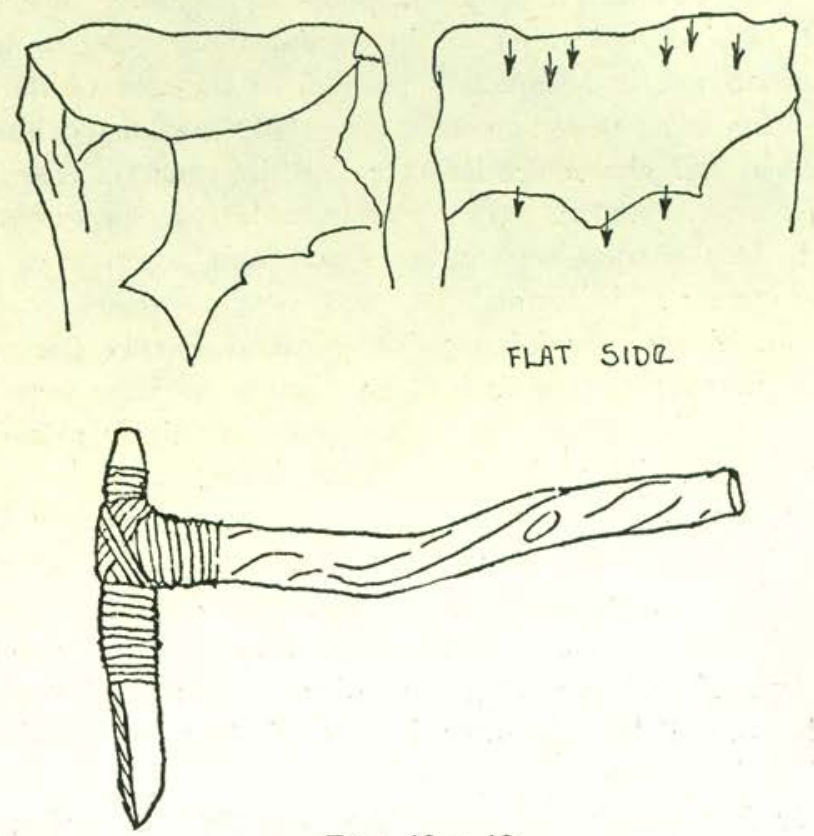

Figs. 12 y 13.

2. Great length $(11.0 \mathrm{~cm}$. to $15.7 \mathrm{~cm}$.) in proportion to width (3-4 cm.), producing a tool which fits comfortably into the hand.

3. Heavy striations and often polishing over most of the cutting edge of the tool and parts of the body, heavier on the underside than in the channel.

4. Some pounding scars on the poll, though sometimes the poll has been shattered and re-chaped.

The specimen eaxmined most closely (n: 526, Fig. 11) showed a consistent diagonal pattern of striation over the front $5 \mathrm{~cm}$. of the tool. This indicates that the tool was twisted counter-clockwise as it was pounded into the wood, removing a larger chip thereby. 
These wood-working tools were probably used in conjuction with true adzes, of which three specimens were correctly identified by Willey. These were originally named Plano-Convex; small variety Adzes or Planes, and are confirmed as such by micro-analysis. It is likely that the seven tools classified as Bifacial Elongated; Adzes or Planes were acutally chisels or gouges leaving only the three mentioned above as true adzes. Illustrated in Fig. 12, their diagnostic attributes are:

1. One flat side exhibiting little or no chipping.

2. Small size, ranging from 5 to $7 \mathrm{~cm}$. in length and 5.3 to 4.3 $\mathrm{cm}$. in width.

3. Unpounded or marked poll end; relatively straight bit.

4. Wear pattern and stritions only on the flat side of the bit end, with all striations running perpendicular to the edge.

A common method of hafting an adze is illustrated in Fig. 13, and the lack of haft-marks on the Barton Ramie specimen may indicate that a similar method was used by the Mayas. An alternative possibility may be found in Fig. $4 \mathrm{~d}$,e, or the tool may have been hafted transversally in a short handle and used in the manner of a plane.

Wear - analysis of the fourteen drills recovered from Barton Ramie was highly inconclusive. A granular chert seems to have been selected for most of these tools, perhaps berause of its lesser susceptability to shattering. Unfortunately this material, as noted previously, does not readily show wear patterns. The most that can be said is that these implements were definitely heavily used, as there was significant blunting of the point. This wear however, cannot be definitely ascribed to drilling, and punching, engraving or splitting can be suggested as alternate uses to which this tool may have been put. Ethnographic data suggests that for many drilling functions wood or reed in conjunction with sand was used instead of stone.

It is hoped that the information contained in this article will be of some use to those involved in the business of interpreting Mayan remains. It is important to remember though, that wear analysis is in its "Early Formative" stage, and that all the conclusions I have reached here are subject to modification due to the input of new data and to suggestion and criticism from colleagues. Thanks are due here to Dr. Gordon Willey for his kind help and encouragement in the preparation of this report, for his suggestions for it's improvement, and for permission to criticize his original report. 


\section{BIBLIOGRAPHY}

Coz, W. R., Piedras Negras Archaeology: Artifacts, Caches and Burials. University Museum Monographs, University of Pennsylvania, Philadelphia, 1959.

Seminov, S. A., Prehistoria Technology; Cory, Adams and Mackay, London, 1964.

Trompson, J. E. S., A Commentary on the Dresden Codex, American Philosophical Society, Philadelphia, 1972.

Willey, G. R., Prehistoric Maya Settlements in the Belize Valley, Papers of the Peabody Museum, Harvard University, Vol. 54, Cambridge, 1965.

The Artifacts of Altar De Sacrificios, Papers of the Peabody Museum, Harvard University, Vol. 64, No. 1, Cambridge, 1972. 